\title{
Triangular fibrokartilaj kompleks yaralanmalarının açık cerrahi tedavisi
}

\section{Open surgical repair of the triangular fibrocartilage complex injuries}

\author{
Halil ibrahim Bekler
}

Avicenna Ataşehir Hastanesi, İstanbul

Triangular fibrokartilaj kompleksi distal radyoulnar ile ulnokarpal eklemi birleştiren ve tespit eden yumuşak dokular sistemidir. Bu yapı; birçok bağdan, bir menisküs benzerinden ve eklem diskinden oluşur. Distal radyoulnar eklem (DRUE) instabilitesinde en önemli bağlar, dorsal ve volar radyoulnar bağlardır. Triangular fibrokartilaj kompleks yaralanmaları el bileği ulnar taraftaki ağrıların ve DRUE eklem instabilitesinin en sık sebebidir. Triangular fibrokartilaj kompleks yaralanmalarının onarımı için açık ya da artroskopik birçok cerrahi teknik önerilmiştir. Açık cerrahide dorsal ve palmar yaklaşımlar önerilmektedir. Ancak triangular fibrokartilaj kompleks onarımı için en ideal yaklaşım ve işlem halen tartışmalıdır.

Anahtar sözcükler: triangular fibrokartilaj kompleksi; distal radyoulnar eklem; yırtık; açık onarım
The triangular fibrocartilage complex (TFCC) is a soft tissue complex that spans and stabilizes the ulnocarpal joint and the distal radioulnar joint (DRUJ). The complex consists of several ligaments, a meniscal homolog, and an articular disk. The most critical ligaments of DRUJ instability include the dorsal and volar radioulnar ligaments. Triangular fibrocartilage complex tears are a common source of ulnar-sided wrist pain and distal radioulnar joint instability. Several surgical procedures to repair TFCC foveal tear have been proposed, including open and arthroscopic TFCC repairs. Dorsal or a palmar surgical approaches have also been proposed. However, the ideal procedure and approach for TFCC foveal tear remain controversial.

Key words: triangular fibrocartilage complex; distal radioulnar joint; tear; open repair

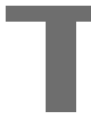
riangular fibrokartilaj kompleksi (TFKK), distal radyoulnar eklemin (DRUE) önemli bir stabilizatörüdür. Aynı zamanda, karpal kemiklerle distal ulna arasında yük aktarımını sağlar. TFKK, triangular fibrokartilaj (eklem diski) palmar ve dorsal radyoulnar bağ, meniskal homolog, ulnar kollateral bağ ve ekstansör karpi ulnaris (EKU) tendon yatağından oluşur. TFKK yaralanmalarında tam tarif edilemeyen bir ulnar taraf ağrısı ve ön kol rotasyonlarında klik hissi gözlenir.

Bu kompleksin yaralanmalarının en ciddi sonucu distal radyoulnar eklem instabilitesidir. DRUE bir diartrodial trokoid eklemdir, ulna ve radius distal bağlantısını sağlar. Uyumu az bir eklemdir, yalnızca \%20 stabilite kemiksel temas ile sağlanır. Radius sigmoid çentiği ulna radyal kenarına oranla daha geniştir, bu nedenle TFKK'nin oluşturduğu yumuşak dokular stabilite açısından çok önemlidir. ${ }^{[1]}$

DRUE öncelikle, ulna foveasından köken alan, dorsal ve palmar radyoulnar bağlar ile stabilize edilir. Palmar radyoulnar bağ, radiusun ulnaya oranla palmara kaymasının ve supinasyonunun önündeki ana engeldir. Tersine, dorsal translasyon ve pronasyon dorsal radyoulnar bağ tarafindan engellenir. ${ }^{[2]}$

İnterosseöz membranın, ekstansör retinakulumun ve kas-tendon kuwvetlerinin stabiliteye katkılarını da unutmamak gereklidir. Kronik olgularda konservatif tedavilerden yarar sağlanmamışsa, ya da özel durumlarda; akut DRUE instabilitelerinde, stabil olmayan ve deplase kırıklarda cerrahi tedavi önerilir. Cerrahi

- İletişim adresi: Prof. Dr. Halil İbrahim Bekler, Avicenna Ataşehir Hastanesi, İstanbul

Tel: 0542 -4148969 e-posta: hbekler@yahoo.com

- Geliștarihi: 21 Nisan $2021 \quad$ Kabul tarihi: 7 Mayıs 2021

ORCID iD: Halil İbrahim Bekler, 0000-0002-1054-4816 
tedavilerde dejeneratif olgularda ulnar kısaltma girişimlerinin yanında, açık ya da artroskopik TFKK tamir ya da debridmanları uygulanır.

\section{KLINIK INCELEME}

El bileği ulnar yerleşimli ağrılarının ana nedenlerinden olan triangular fibrokartilaj kompleks yaralanmaları aşıı pronasyondaki el bileğinin aksiyel yüklenmesi ile oluşur. Stabil olmayan bir TFKK yaralanmasında radiusa göre ulna başı dorsalde belirgindir. Pronasyonda ulna başı yerine redükte edilebilir. Bu his ve yarattı̆̆ ağrıya piyano bulgusu adı verilir. ${ }^{[3]}$ Ön-arka planda radyoulnar eklemde aşırı yer değiştirme gözlenir, karşı sağlam el bileğiyle karşılaştırma yapılmalıdır.

Volarde fleksör karpi ulnaris (FKU), pisiform, trikuetrum ve ulnar stiloid arasında kalan çukurda (foveada) hassasiyet TFKK yaralanmaları için \%95 sensitif, \%86 spesifiktir. ${ }^{[4]}$

Radyolojik incelemede iki taraflı arka-ön ve yan grafiler (nötral pozisyonda) ve ulnar varyansı saptamak amacıyla pronasyonda grafi istenir. Manyetik rezonans (MR) görüntüleme ve $M R$ artrografi açık ya da artroskopik cerrahi endikasyonu için gereklidir. TFKK yaralanmalarını gösterdiği gibi ulnar impaksiyon EKU tendiniti gibi olası ayırıcı tanıların da ayrımının yapılmasını kolaylaştırmaktadır.

Açık TFKK onarımları, bu yaralanmaların ilk tarif edilmiş ve kendini kanıtlamış tedavi biçimidir. ${ }^{[5]}$ Son dönemde yeni artroskopik teknikler TFKK bölgesinin anatomik yapılarının görüntülenmesini artırmış, cerrahi sırasında çevre dokuların tahrip edilme oranını azaltmıştır. Artroskopik onarımlar daha az invaziv olmasına rağmen bazı cerrahlar halen triangular fibrokartilaj (TFK) fovea bağlantısının anatomik onarımlarında açık cerrahiyi tercih etmektedir. ${ }^{[6,7]}$

Cooney ve ark., açık cerrahi tekniği dorsal bir insizyonla 4. ve 5. ekstansör kompartmanlar arasından ekleme ulaşılacak şekilde tarif etmişlerdir. Ekstansör retinakulum devrildikten sonra ulnar eklem kapsülü TFKK'ye paralel bir şekilde keskin disseksiyonla açılır. Radyal taraf yırtıkları için DRUE içinde de TFK'nın proksimaline uzanan bir kesi yapılır. Bu kesiler ile yırtık ya da yıpranmanın yerleşimi ve yayılımı ortaya konulur.

\section{CERRAHI TEKNIK}

Ameliyat genel ya da blok anestezi altında yapılabilir. Ameliyat öncesi antibiyotik profilaksisinden sonra turnike sistolik basınca göre uygulanır. DRUE merkeze alacak şekilde el bileği dorso-ulnarında uzunlamasına bir kesi yapılır (Şekil 1). Kesi ulnar sinirin dorsal duyusal dalına paraleldir. Gereğinden fazla ulnara kayılırsa bu sinirin zedelenme tehlikesi vardır. Ulnar sinirin dorsal duyusal

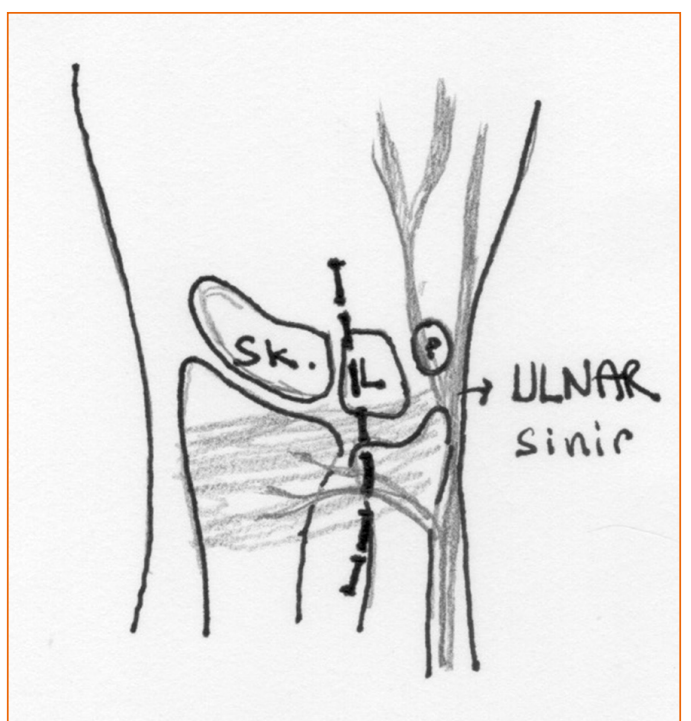

Şekil 1. Distal radyoulnar eklem üzerinde yapılacak kesi ulnar sinir dorsal duyusal dalına paraleldir (Sk, skafoid; L, lunatum; $P$, pisiform).

dalının da yan dalı olan transvers retinakular sinir ekstansör retinakulum proksimalinde seyreder. Ekstansör retinakulum, ekstansör karpi ulnaris tendonu radyal kenarı boyunca radyal bazlı bir flep şeklinde kaldırııır ve bu flep işlem sonunda yerine özenle dikilir. EKU'nun deplase olması önlenir. Retinakulum kaldırıldığında 5 . ve 6. ekstansör kompartman ulnara çekilerek ulno-karpal eklem dorsal kapsülüne ulaşılır (Şekil 2). Parmaklara "parmak tuzağg" benzeri yöntem ile uygulanacak traksiyonla görünüm daha rahat hale gelebilir.

"T" ya da " $L$ " şeklinde bir insizyon ile ulnokarpal kapsülotomi yapılır, bu sırada kapsülü tam olarak ortalayan 5. parmak ekstansörü, ekstansör dijiti minimi ve ekstansör dijiti kuinti radyal ya da ulnara alınarak eksplorasyon rahatlatılır. " $T$ " insizyonunun yatay hattının TFK'nin distalinden geçmesine TFK'da ek yaralanmaya sebep olmamak için özen gösterilmelidir (Şekil 3).

Kapsüler flepler kaldırıldığında ulnokarpal eklem ve TFK özellikle parmaklara uygulanan traksiyonla görünür hale gelir. İnce kibar yuvarlak kenarlı bir elevatör (Freer) lunatum ile radius arasına lunat fossaya sokulduğunda eklem daha rahat görülür. Tercihen ikili bir hook (çengel) ile triangular fibrokartilaj kenarından kaldırılır ve hasarlı alan daha kolay görülür.

Sıklıkla medial ya da dorsomedialde bulunan TFK kopmuş, yırtık ya da yıpranmıştır. Fibrotik granülasyon dokusu küret ya da ronjör kullanılarak temizlenir. TFK'nın daha yumuşak sarımsı ve hiperemik granülasyon dokusundan ayrımı genellikle kolaydır. 


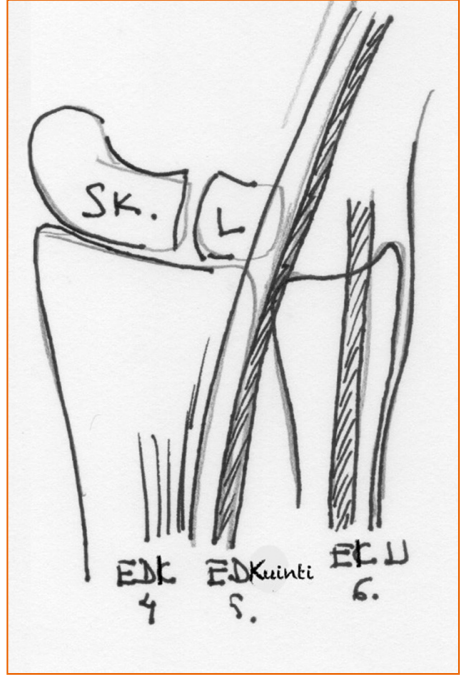

Şekil 2. EDK ve EDKuinti klivajından; 4-5. kompartmanlar arasından eklem kapsülüne ulaşılır (SK, skafoid; L, lunatum; EDK, ekstansör dijitorum kommunis; EDKuinti, ekstansör dijiti kuinti; EKU, ekstansör karpi ulnaris).

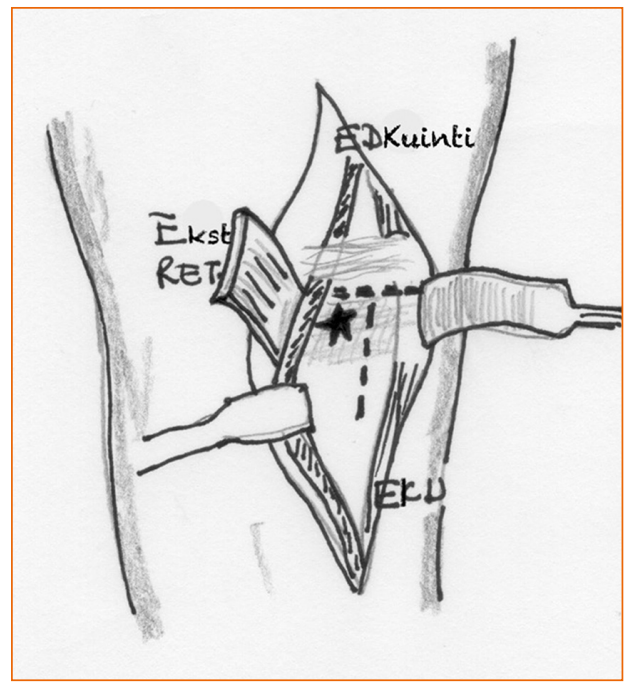

Şekil 3. "T" ya da "L" şeklinde bir insizyon ile ulnokarpal kapsülotomi yapılır. "T" insizyonunun yatay hattının triangular fibrokartilajın (TFK'nın) distalinden geçmesine dikkat edilmelidir (EKU, ekstansör karpi ulnaris; Ekst ret, ekstansör retinakulum; EDKuinti, ekstansör dijiti kuinti).
Ulnar stiloid sulkus tabanında spongiyoz (süngerimsi) sağlıklı kemik bulunur (Şekil 4). Ulna medial kenarı proksimalinden sulkusta hazırlanan bölgeye doğru uzanan aralarında 8-9 mm uzaklık bulunan iki tünel $1 \mathrm{~mm}$ Kirschner teli (K-teli) yardımı ile açılır (Şekil 5). Bu tüneller yardımı ile TFK vasküler periferik alanına mattress teknikle uygulanmış ve $3 / 0$ non-absorbabl (emilmeyen) dikişler pull-out yöntemi ile medial ulna kenarına geçirilir (Şekil 6).

Triangular fibrokartilaj pull-out dikiş ile yerine tespit edilmeden önce, nötral pozisyonda distalde ulna medialinden radiusa uzanan bir K-teli ile rotasyonel tespit yapılır. Eğer ulna ve radius stabil ise TFK ulnaya mümkün olduğunca sıkı bir şekilde tespit edilir (Şekil 6). Açılmış olan radyoulnar eklem dorsal kapsülünün uzunlamasına hattı emilmeyen (absorbe olmayan) dikişler ile onarılır, transvers hat ise açık bırakılır. Retinakular bağ EKU tendonuna onarılır ya da retinakulum flebi EKU etrafindan dolanarak EKU'nun ulnara kaçması engellenir.

$\mathrm{Bu}$ tekniğe uygun şekilde 33 hastayı tedavi eden Cooney ve ark., Mayo modifiye el bilek skoru (MMWS)

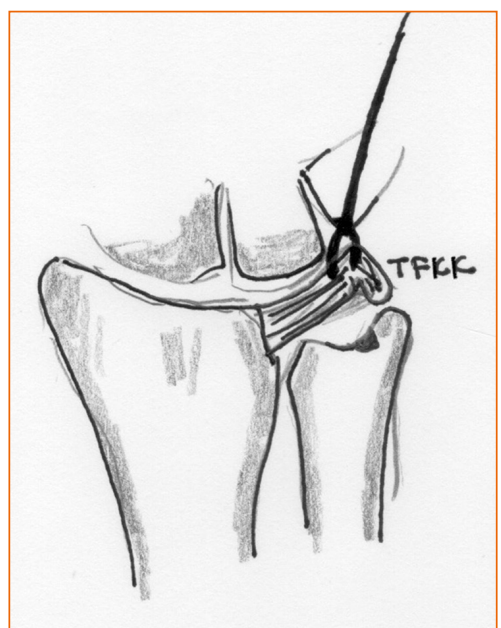

Şekil 4. Ulnar stiloid sulkus tabanında spongiyoz kemik bulunur (TFKK, triangular fibrokartilaj kompleksi).

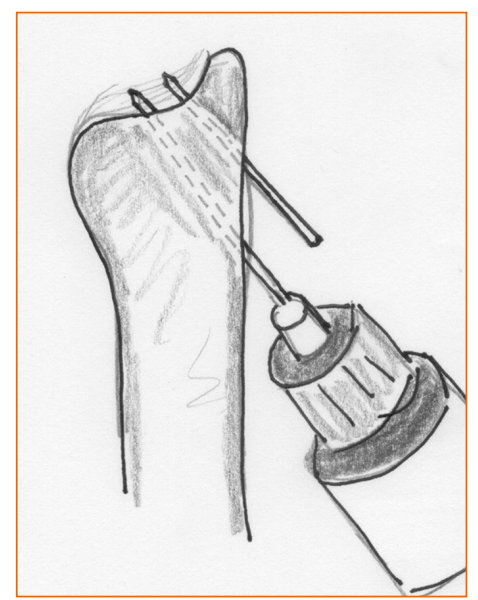

Şekil 5. Ulna medial kenarı proksimalinden sulkusta hazırlanan bölgeye doğru uzanan aralarında 8-9 mm uzaklık bulunan iki tünel Kirschner teli $(1 \mathrm{~mm})$ yardımı ile açılır. 


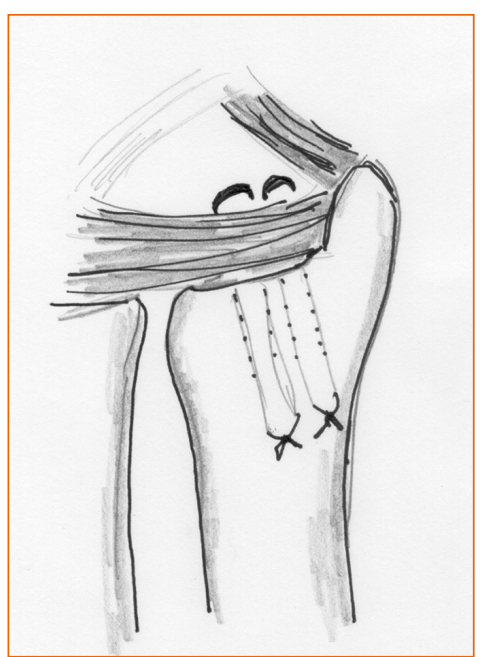

Şekil 6. Triangular fibrokartilaj (TFK) ulnaya mümkün olduğunca sıkı bir şekilde tespit edilir.

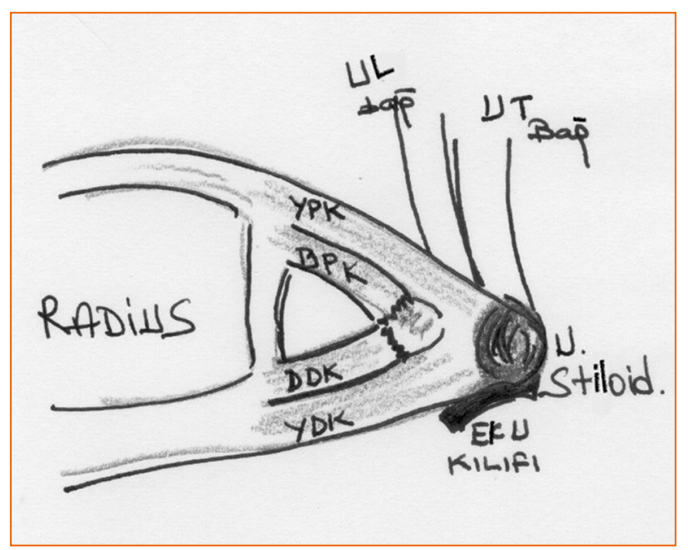

Şekil 7. Triangular fibrokartilaj kompleksi (TFKK) ulnanın distaline derin palmar kol, derin dorsal kol, yüzeyel palmar kol ve yüzeyel dorsal kol ile bağlanmaktadır (YPK, yüzeyel palmar kol; DPK, derin palmar kol; DDK, derin dorsal kol; YDK, yüzeyel dorsal kol; UL bağ, ulnolunat bağ; UT bağ, ulnotrikuetral bağ; U. stiloid, ulnar stiloid; EKU, ekstansör karpi ulnaris). ile 11 mükemmel, 15 iyi ve yedi orta-hafif sonuç bildirmişlerdir. ${ }^{[5]}$ Anderson ve ark. ise, açık teknikle yaptıkları TFKK onarımlarında yine MMWS'ya göre 39 hastadan 17'sinde mükemmel ve dokuzunda iyi sonuç bildirmişlerdir. ${ }^{[8]}$ Ruch ve ark., 2003 yılında Arthroscopy dergisinde yayımlanan biyomekanik çalışmalarında açık metotta kullanılan transosseöz metodla daha çok artroskopik teknikte kullanılan EKU kılıfı ve dorsal ulnokarpal kapsüle TFK'yı dikme tekniğini karşılaştırmışlar ve aralarında anlamlı bir fark bulunmayan her iki tekniğin de başarılı olduğunu gözlemlemişlerdir. ${ }^{[9]}$ Daha yeni bir çalışma çapa (ankor) kullanılarak yapılan açık onarım ile artroskopik transosseöz onarımı karşılaştırmış ve artroskopik transosseöz yöntemin çapaya oranla daha stabil olduğunu göstermiştir. Ancak bu çalışmada her ne kadar artroskopik transosseöz karşılaştırılıyor denilse de her iki grup kadavrada açık cerrahi yöntemle hazırlanmıştır ve ankor ile transosseöz yöntem karşılaştırılmaktadır. Açık cerrahi onarımda transosseöz tespit çok daha güvenilir yöntemdir, tespit daha iyi olmakta ve gerginlik daha iyi ayarlanmaktadır. ${ }^{[10]}$

Genel olarak TFK yaralanmaları dorsalden onarılırken bazı yazarlar dorsal yaklaşımda radyoulnar bağın dorsal kısmının ve EKU kılıfının fovea lezyonlarının görülmesini engellediğini bildirmişlerdir.

Triangular fibrokartilaj kompleksi, ulna distaline dört ana yapı ile bağlanmaktadır. Bunlar derin palmar kol, derin dorsal kol, yüzeyel palmar kol ve yüzeyel dorsal koldur. TFKK yaralanmalarına bağlı olan DRUE instabilitelerinde radiusun volare subluksasyonu çok daha sık görülmektedir ve bu volare doğru instabilitenin tedavisinde derin palmar kolun onarımı çok önemlidir. Palmar yerleşimli bu dokunun dorsalden görülmesi, lezyonun ortaya konması ve onarımı güç olmaktadır. Derin palmar kolun dorsalden onarımı sırasında dorsal radyoulnar bağın yüzeyel kolu ve EKU kılıfi yaralanmaktadır (Şekil 7). Bu dokuların kesilmesinin gerektiği ve bunun da instabiliteyi artırdığı bildirilmiş̧ir. Alternatif olarak TFKK onarımlarında palmar yaklaşım önerilmektedir. ${ }^{[11]}$

\section{PALMAR YAKLAŞIMLA CERRAHI TEKNIK}

Bu yaklaşımda klasik turnike, genel ya da bölgesel anestezi altında uygulanır. Ön kol supinasyondadır. Fleksör karpi ulnaris (FKU) tendonu üzerinde pisiform kemiğin ulnarında zigzag kesi uygulanır (Şekil 8). FKU tendonu ve ulnar sinir bulunur, radyale alınır. Ulnar sinir dorsal kutanöz dalı ise ulnara alınır. FKU kılıfı ile pisiformu birleştiren derin fasya kesilir. DRUE palmar kapsülü radius sigmoid çentik distalinde ulnar stiloid bazisine uzanan transvers kesi ile açılır.

Yaralanmış TFKK distale çekilerek foveal lezyon kolayca görünür hale gelir. Ulnokarpal ligaman kompleksi palpasyonla kolayca bulunur, ulnotrikuetral bağ ve FKU kılıfi tabanı arasında bulunan medial ulnokarpal eklem kapsülünün yumuşak bölümü eksize edilerek ortaya konur. ${ }^{[12]}$

Pisotrikuetral eklem kapsülünün eksizyonu UKLK'nin daha iyi görülmesini sağlar. TFKK'nin foveal ve stiloid bağlantıları distal ve proksimalden incelenir. Ulnar yapışma bölgesi ayrılmış ise ya da skar (nedbe dokusu) ile dolu ise skar kürete edilir, ankor ile onarım yapılır.

Biyomekanik olarak daha önemli olan TFKK palmar kısmının iyatrojenik olarak yaralamadan onarımının palmar yaklaşımla daha kolay olacağı ileri sürülmektedir. ${ }^{[13]}$ 


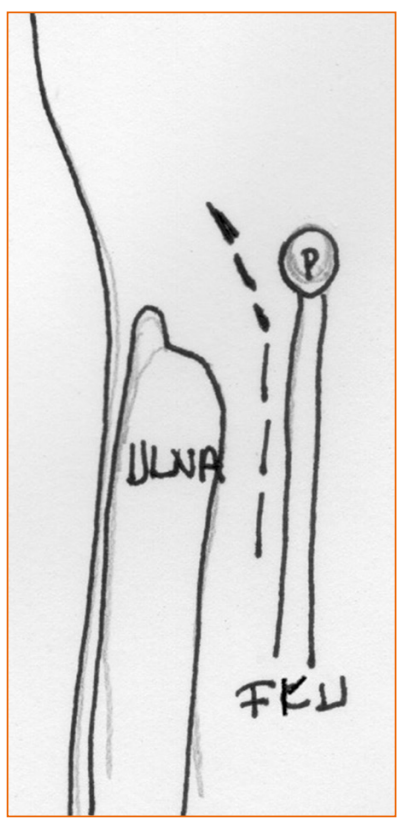

Şekil 8. Pisiform (P) kemikten proksimale uzanan fleksör karpi ulnaris (FKU) ile ulna arasından kesi yapılır.

TFKK yırtıklarını ve tedavilerini ilk tarif edenlerden olan Mayo Klinik tarafından 2008 yılında yapılan artroskopik ve açık cerrahi karşılaştırılmıştır. Bu yayında açık cerrahi sonrası sağlam tarafa oranla $\% 79$ supinasyon-pronasyon ve $\% 68$ oranında fleksiyon-ekstansiyon hareketi elde edilmiştir. Artroskopik grupta bu oranlar prono-supinasyonda \%81 ve fleksiyon-ekstansiyonda $\% 72$ olarak bulunmuştur. ${ }^{[8]}$

Kavrama kuvveti ise açık cerrahi sonrası sağlam el bileğinin \%73'ü ve artroskopik grupta \%71'i olarak ölçülmüştür. Bu bulguların Trumble ve ark.'nın verileriyle uyumlu olduğunu söyleyen yazarlar açık ve artroskopik cerrahi sonrası oluşan hareket kısıtlamalarına dikkati çekmişlerdir. Aynı çalışmada açık cerrahi uygulanan hastalarda çok daha sık oranda sinir yaralanması ve EKU tendinitine rastlandığı bildirilmiştir. Ancak artroskopik grupla açık cerrahi uygulanan grup arasında başarı oranında istatistiki bir fark gözlenmediği vurgulanmıştır. ${ }^{[8]}$

Andersson ve ark., tarafindan 2018'de yayımlanan bir meta-analizde TFKK'nin açık ya da artroskopik onarımlarından sonra DRUE instabilitesinin tekrarlamasında fark bulunmamıştır. Ayrıca eklem hareket açıklığı ya da kavrama gücü ve fonksiyonel skorlamalar açısından farklılığa rastlanmamıştır. ${ }^{[14]}$

TFKK yaralanmaları artroskopik olduğu gibi açık cerrahi yöntemlerle de tedavi edilebilirler. Açık cerrahi tedavi sırasında sıklıkla Cooney ve ark.'nın tarif ettiği dorsal yöntem kullanılmaktadır. Ancak volar yaklaşım da açık cerrahi sırasında güvenle kullanılabilen bir tekniktir. Artroskopik tedavi seçeneğinin komplikasyon oranları daha düşük olarak bildirilmiştir. Klinik başarı oranlarında açık ya da artroskopik yöntemler arasında istatistiki fark bulunamamıştır. ${ }^{[5]}$

Açık cerrahi TFKK onarımları cerrahın tercihine bağlı olarak kullanılabilen başarılı yöntemlerdir. Artroskopik cerrahi teknikte ekipman gerekliliği ön plandadır, bu ekipmanın sağlanamadığı ortamlarda açık cerrahi bir seçenek olarak cerrahın elinde olmalıdır.

\section{KAYNAKLAR}

1. Stuart PR, Berger RA, Lischeid RL, An KN. The dorsopalmar stability of the distal radioulnar joint. J Hand Surg Am 2000;25(4):689-99. Crossref

2. Kihara H, Short WH, Werner FW, Fortino MD, Palmer AK. The stabilizing mechanism of the distal radioulnar joint during pronation and supination. J Hand Surg Am 1995;20(6):9306. Crossref

3. Adams BD, Fraser JL. The Distal Radioulnar Joint. In: Wolfe SW, Pederson WC, Hotchkiss RN, Kozin SH, Cohen MS. Green's Operative Hand Surgery, 7th ed. Philadelphia, PA: Elsevier; 2017. p.479-513.

4. Tay SC, Tomita K, Berger RA. The "ulnar fovea sign" for defining ulnar wrist pain: an analysis of sensitivity and specificity. J Hand Surg Am 2007;32(4):438-44. Crossref

5. Cooney WP, Linscheid RL, Dobyns JH. Triangular fibrocartilage tears. J Hand Surg Am 1994;19(1):143-54. Crossref

6. Sagerman SD, Short W. Arthroscopic repair of radialsided triangular fibrocartilage complex tears. Arthroscopy 1996;12(3):339-42. Crossref

7. Trumble TE, Gilbert M, Vedder N. Arthroscopic repair of the triangular fibrocartilage complex. Arthroscopy 1996;12(5):588-97. Crossref

8. Anderson ML, Larson AN, Moran SL, Cooney WP, Amrami KK, Berger RA. Clinical comparison of arthroscopic versus open repair of triangular fibrocartilage complex tears. J Hand Surg Am 2008;33(5):675-82. Crossref

9. Ruch DS, Anderson SR, Ritter MR. Biomechanical comparison of transosseous and capsular repair of peripheral triangular fibrocartilage tears. Arthroscopy 2003;19(4):3916. Crossref

10. Ma CH, Lin TS, Wu CH, Li DY, Yang SC, Tu YK. Biomechanical comparison of open and arthroscopic transosseous repair of triangular fibrocartilage complex foveal tears: A cadaveric study. Arthroscopy 2017;33(2):297-304. Crossref

11. Moritomo $\mathrm{H}$. Advantages of open repair of a foveal tear of the triangular fibrocartilage complex via a palmar surgical approach. Tech Hand Up Extrem Surg 2009;13(4):176-81. Crossref

12. Garcia-Elias M. Soft-tissue anatomy and relationships about the distal ulna. Hand Clin 1998;14(2):165-76. Crossref

13. Moritomo $\mathrm{H}$. Open Repair of the triangular fibrocartilage complex from palmar aspect. J Wrist Surg 2015;4(1):2-8. Crossref

14. Andersson JK, Åhlén M, Andernord D. Open versus arthroscopic repair of the triangular fibrocartilage complex: a systematic review. J Exp Orthop 2018;13;5(1):6. Crossref 